\title{
Distinctive Electrophoretic and Isoelectric Focusing Patterns of Esterases from Yersinia enterocolitica and Yersinia pseudotuberculosis
}

\author{
By Ph. GOULLET* AND B. PICARD \\ Laboratoire de Microbiologie, Faculté de Médecine Xavier-Bichat (Université Paris VII), \\ 16 rue Henri Huchard, 75018 Paris, France
}

(Received 16 December 1983; revised 14 February 1984)

\begin{abstract}
Esterases of 53 strains of Yersinia enterocolitica sensu stricto, including five previously defined biotypes, and 30 strains of Yersinia pseudotuberculosis were analysed by horizontal polyacrylamide-agarose gel electrophoresis and by isoelectrofocusing in thin-layer polyacrylamide gel. Esterase bands were defined by their range of activity towards several synthetic substrates, their resistance to heat and to di-isopropyl fluorophosphate. The two species were characterized by distinct electrophoretic patterns of their esterases. The apparent molecular weights of the heat-resistant esterase of $Y$. enterocolitica and of the major heat-resistant esterase of $Y$. pseudotuberculosis, as determined by polyacrylamide gradient gel electrophoresis, were estimated to be 52000 and 250000 , respectively. On the basis of electrophoretic mobilities and isoelectric points of esterases produced by strains of $Y$. enterocolitica, five principal zymotypes were observed: two for strains of biotype 1, two for strains of biotypes 2 and 3, respectively, and only one for strains of both biotypes 4 and 5. The zymotypes of strains of biotypes 2, 3, 4 and 5 appeared to be more closely related to one another than to zymotypes of strains of biotype 1 . Variations in number or mobility of bands observed within each biotype of $Y$. enterocolitica and within some serotypes of $Y$. pseudotuberculosis could represent an additional marker for epidemiological analysis.
\end{abstract}

\section{INTRODUCTION}

Yersinia enterocolitica and Yersinia pseudotuberculosis, causative agents of diverse human and animal diseases, are distinguishable from one another by both conventional biochemical tests and DNA hybridization (Brenner et al., 1976). Strains of Y.pseudotuberculosis were found to be homogeneous in DNA relatedness and relatively uniform in biochemical tests, whereas $Y$. enterocolitica strains were found to be genetically and biochemically heterogeneous (Brenner $e t$ al., 1976; Harvey \& Pickett, 1980; Kaneko \& Hashimoto, 1982).

Bercovier et al. $(1980 a)$ have defined the species $Y$. enterocolitica sensu stricto $(S S)$ which contains five major biotypes based on reactions for lipase, DNAase, Indole, D-xylose, sucrose, Dtrehalose and $\mathrm{NO}_{3}^{-}$reduction to $\mathrm{NO}_{2}^{-}$. This species which forms one DNA relatedness group (Brenner $e t$ al., 1980a) is distinct from the newly described species $Y$. intermedia (Brenner et al., 1980b), Y. frederiksenii (Ursing et al., 1980) and Y. kristensenii (Bercovier et al., 1980b).

The present work, which extends previous research on enterobacterial esterases (see Goullet, $1980 a, b, 1981)$, proposes a new phenotypic approach for both specific and intra-specific differentiation of $Y$. enterocolitica $(S S)$ and $Y$. pseudotuberculosis by electrophoretic and isoelectrofocusing patterns of their esterases.

Abbreviation: DFP, di-isopropyl fluorophosphate. 


\section{METHODS}

Bacterial strains. The names and sources of the test strains are given in Table 1. Cultures were incubated at $28^{\circ} \mathrm{C}$.

Growth conditions, preparation of extracts, protein estimation, horizontal slab polyacrylamide-agarose gel electrophoresis, estimation of electrophoretic mobility $\left(M_{F}\right.$ value), polyacrylamide gradient gel electrophoresis and esterase staining. These have all been described previously (Goullet, 1980a).

Enzymic tests and substrates. The substrates used were $\alpha$ - and $\beta$-naphthyl acetates, $\alpha$ - and $\beta$-naphthyl butyrates and indoxyl acetate. Heat inactivation and inhibition by di-isopropyl fluorophosphate (DFP) were as previously described (Goullet, 1980a).

Isoelectric focusing. Thin-layer isoelectric focusing on polyacrylamide gel (Vesterberg \& Svensson, 1966) was performed in Pharmacia flat bed electrophoresis apparatus FBE 3000, maintained at $4{ }^{\circ} \mathrm{C}$ by a circulating-water bath (LKB 2209 Multitemps). Ampholine LKB of pH range 3.5 to 10, Pharmalyte of pH range 4 to 6.5 and Pharmalyte of $\mathrm{pH}$ range 5 to 8 were used.

Before application of the cell extracts, gels were pre-electrofocused for $30 \mathrm{~min}$ at a constant power of $25 \mathrm{~W}$ (Pharmacia electrophoresis constant power supply ECPS 2000/300). Samples at a protein concentration of 50 to $60 \mathrm{mg} \mathrm{ml}^{-1}$ were absorbed into a strip $(20 \times 2 \mathrm{~mm}$ ) of filter paper (Whatman no. 3) which was applied to the gel, $10 \mathrm{~mm}$ from the cathode.

Focusing was conducted for $2 \mathrm{~h}$. The sample application paper was removed after $30 \mathrm{~min}$. The gel was stained for esterase activity by the same technique as for electrophoresis. For determination of the $\mathrm{pH}$ gradient, pieces of gel $4 \mathrm{~mm}$ long and $10 \mathrm{~mm}$ wide were cut from the gel and eluted in $0.4 \mathrm{ml} 10 \mathrm{~mm}-\mathrm{KCl}$ solution; $\mathrm{pH}$ was measured at $20^{\circ} \mathrm{C}$ and a pH curve was obtained for each gel by plotting the $\mathrm{pH}$ value against the distance measured from the edge of the gel. The pI of esterase was determined by interpolation from this curve.

\section{Table 1. Strains examined}

\section{Yersinia enterocolitica}

\begin{tabular}{|c|c|c|c|c|c|}
\hline Code & Strain $\dagger$ & Biotype $\ddagger$ & Serotype $\S$ & $\begin{array}{l}\text { Phage } \\
\text { typingll }\end{array}$ & Source \\
\hline $1^{*}$ & $96(a)$ & 1 & $0: 4$ & $\mathbf{X}_{\mathbf{Z}}$ & Chinchilla, Denmark \\
\hline $2^{*}$ & $106(a)$ & 1 & $0: 7$ & $\mathbf{X}_{\mathbf{Z}}$ & Guinea pig, Denmark \\
\hline $3^{*}$ & $124(a)$ & 1 & $0: 5$ & $X_{Z}$ & Colt, France \\
\hline $4^{*}$ & $161(a)$ & 1 & $0: 8$ & $X_{Z}$ & Human, USA \\
\hline 5 & $846(a)$ & 1 & $0: 18$ & $X_{0}$ & Human, USA \\
\hline $6^{*}$ & $1646(a)$ & 1 & $0: 6$ & $\mathbf{X}_{\mathbf{Z}}$ & Human, Czechoslovakia \\
\hline $7^{*}$ & $3419(a)$ & 1 & $\mathrm{O}: 8$ & $X_{Z}$ & Human, Canada \\
\hline $8^{*}$ & $3865(a)$ & 1 & $0: 8$ & $\mathrm{X}_{\mathrm{Z}}$ & Human, Canada \\
\hline $9^{*}$ & $9020(a)$ & 1 & $0: 5$ & $\mathbf{X}_{\mathrm{Z}}$ & Raw milk, France \\
\hline $10^{*}$ & $9023(a)$ & 1 & $0: 10$ & $\mathbf{X}_{\mathbf{Z}}$ & Raw milk, France \\
\hline $11^{*}$ & $10389(a)$ & 1 & $0: 6$ & $\mathbf{X}_{\mathbf{Z}}$ & Human, Italy \\
\hline $12^{*}$ & $10414(a)$ & 1 & $0: 27$ & $X_{Z}$ & Human, Belgium \\
\hline $13^{*}$ & $10649(a)$ & 1 & $0: 4$ & $\mathrm{X}_{\mathrm{Z}}$ & Human, France \\
\hline $14^{*}$ & $10660(a)$ & 1 & $0: 7.8$ & $X_{0}$ & Human, France \\
\hline 15 & $2.75(b)$ & 1 & $0: 6$ & $X_{Z}$ & Rodent, France \\
\hline $16^{*}$ & $211(a)$ & 2 & $0: 9$ & $\mathbf{X}_{3}$ & Human, Belgium \\
\hline $17^{*}$ & $336(a)$ & 2 & $0: 9$ & $\mathrm{X}_{3}$ & Human, Sweden \\
\hline $18^{*}$ & $359(a)$ & 2 & $0: 9$ & $\mathbf{X}_{3}$ & Human, Belgium \\
\hline 19 & $373(a)$ & 2 & $0: 9$ & $X_{3}$ & Human, Finland \\
\hline $20^{*}$ & $825(a)$ & 2 & $0: 9$ & $X_{3}$ & Human, Finland \\
\hline $21^{*}$ & $827(a)$ & 2 & $0: 9$ & $X_{3}$ & Human, Finland \\
\hline $22^{*}$ & $8385(a)$ & 2 & $0: 9$ & $X_{3}$ & Human, France \\
\hline $23^{*}$ & $10594(a)$ & 2 & $0: 9$ & $\mathbf{X}_{3}$ & Pig, India \\
\hline $24^{*}$ & $10658(a)$ & 2 & $0: 9$ & $\mathrm{X}_{3}$ & Human, France \\
\hline $25^{*}$ & $10688(a)$ & 2 & $0: 9$ & $X_{3}$ & Human, France \\
\hline $26^{*}$ & $39(a)$ & 3 & $0: 12 \mathrm{a} 3$ & II & Chinchilla, Netherlands \\
\hline $27^{*}$ & $8830(a)$ & 3 & $0: 5$ & $\mathbf{X}_{Z}$ & Human, France \\
\hline $28^{*}$ & $8928(a)$ & 3 & $0: 5$ & $X_{Z}$ & Human, France \\
\hline $29^{*}$ & $8942(a)$ & 3 & $0: 5$ & $X_{Z}$ & Human, France \\
\hline $30^{*}$ & $8969(a)$ & 3 & $0: 5$ & $\mathrm{X}_{\mathrm{Z}}$ & Human, France \\
\hline $31^{*}$ & $8970(a)$ & 3 & $0: 5$ & $\mathrm{X}_{\mathrm{Z}}$ & Human, France \\
\hline $32^{*}$ & $10556(a)$ & 3 & $0: 5$ & $X_{Z}$ & Human, France \\
\hline $33^{*}$ & $10672(a)$ & 3 & $0: 5$ & $\mathrm{X}_{\mathrm{Z}}$ & Pig, Italy \\
\hline
\end{tabular}


Table 1. (continued)

$\begin{array}{lr}34^{*} & 374(a) \\ 35^{*} & 577(a) \\ 36^{*} & 774(a) \\ 37^{*} & 888(a) \\ 38^{*} & 1615(a) \\ 39^{*} & 4975(a) \\ 40^{*} & 8998(a) \\ 41^{*} & 9018(a) \\ 42^{*} & 10674(a) \\ 43^{*} & 10707(a) \\ 44 & 2.77(b) \\ 45^{*} & 1(a) \\ 46^{*} & 27(a) \\ 47^{*} & 37(a) \\ 48^{*} & 178(a) \\ 49 & 425(a) \\ 50^{*} & 489(a) \\ 51^{*} & 2883(a) \\ 52^{*} & 2893(a) \\ 53 & 3662(a)\end{array}$

Code Strain $\dagger$

$2550(a)$

$2552(a)$

$2555(a)$

$2556(a)$

$2558(a)$

$2559(a)$

$2565(a)$

$2568(a)$

$2619(a)$

$2623(a)$

$\mathrm{A} 120(c)$

$55.85(c)$

$2.70(b)$

$2.74(b)$

$14.74(b)$

2553 (a)

$2554(a)$

$2596(a)$

$2613(a)$

$55.86(c)$

2544 (a)

$2549(a)$

$2578(a)$

$1830(a)$

$1833(a)$

$2509(a)$

2463 (a)

$2475(a)$

$1553(a)$

$1554(a)$
$0: 3$

$0: 3$

$0: 3$

$0: 3$

$0: 3$

$0: 3$

$0: 3$

$0: 4$

$0: 3$

$0: 3$

$0: 3$

$\mathrm{O}: 2 \mathrm{a} 2 \mathrm{~b} 3$

$0: 2 \mathrm{a} 2 \mathrm{~b} 3$

$0: 2 \mathrm{a} 2 \mathrm{~b} 3$

$0: 2 \mathrm{a} 2 \mathrm{~b} 3$

$\mathrm{O}: 2 \mathrm{a} 2 \mathrm{~b} 3$

$0: 2 \mathrm{a} 2 \mathrm{~b} 3$

$0: 2 \mathrm{a} 2 \mathrm{~b} 3$

$\mathrm{O}: 2 \mathrm{a} 2 \mathrm{~b} 3$
$0: 2 \mathrm{a} 2 \mathrm{~b} 3$

Yersinia pseudotuberculosis

Serotypef

Blood, Paris, France

Human, France

Human, New Zealand

Ascite, Vannes, France

Blood, Tours, France

Blood, Landes, France

Hare, Sarthe, France

Pig, Italy

Human, England

Sheep, England

Human, Spain

Guinea-pig, Japan

Guinea-pig, Japan
IXb

VIII

VIII

$9 b$

9a

IXa

VIII

VIII

VIII

VIII

VIII

I

XI

II

XIc

I

$\mathrm{XI}$

XI
Human, Montreal, Canada

Human, Czechoslovakia

Human, Belgium

Human, Canada

Pig, Johannesburg, South Africa

Human, Hungary

Human, Spain

Human, Barcelona, Spain

Human, France

Human, Poitiers, France

Human, Bordeaux, France

Hare, France

Hare, France

Hare, France

Hare, England

Hare, France

Hare, France

Goat, Switzerland

Goat, Switzerland

Hare, Hungary

Source

Mesenteric ganglion, Grenoble, France

Blood, Saint-Etienne, France

Blood, Libourne, France

Bovine foetus, Limoges, France

Bovine foetus, Limoges, France

Mesenteric ganglion, Lyon, France

Wild rodent, Bréscia, Italy

Mesenteric ganglion, Bretonneau strain (M. Piechaud) CIP

Strain 14 of E. Thal, (G. Girard) CIP

Blood, La Rochelle, France

Blood, Bordeaux, France

Rabbit, St Brieux, France

Strain 16 of E. Thal (G. Girard) CIP

Pig, Johannesburg, South Africa

Blood, St Cloud, France

Guinea-pig, Lausanne, Switzerland

Guinea-pig, Lausanne, Switzerland

* Strain analysed by isoelectrofocusing.

$\dagger(a)$ Collection of Centre National et Centre Collaborateur O.M.S. pour les Yersinia (Professeur H. H.

Mollaret), Institut Pasteur, Paris, France; (b) Collection of Service des Enterobacteries (Professeur Le Minor), Institut Pasteur, Paris; CIP, Collection de l'Institut Pasteur, Paris.

$\ddagger$ According to the biotyping scheme of Bercovier et al. $(1980 a)$ which derives from the biotyping scheme of Wauters (1970) with slight modifications.

$\S$ According to Wauters et al. (1971).

II According to Nicolle et al. (1967).

T/ According to Thal (1954). 


\section{RESULTS}

Acrylamide-agarose gel electrophoresis

Esterase zymograms obtained by polyacrylamide-agarose gel electrophoresis gave distinctive and reproducible banding patterns for both $Y$. enterocolitica and $Y$. pseudotuberculosis strains. Electrophoretic relationships were established between the strains by multiple runs, comparing esterase bands side by side on the same gel. The $M_{F}$ values were used only comparatively.

Yersinia enterocolitica. The greatest numbers of esterases were detected with $\beta$-naphthyl acetate as substrate. Five bands, designated as $E_{1}, E_{2}, E_{3}, E_{4}$ and $E_{5}$ in order of decreasing mobility towards the anode, and one band $\left(E_{6}\right)$ migrating to the cathode, were defined (Fig. $1 a$ ). Band $E_{1}$ reacted with $\beta$-naphthyl acetate. Band $E_{2}$ was stained by $\alpha$-naphthyl and $\beta$-naphthyl acetates and included two anodic satellite components. Band $E_{3}$ hydrolysed the five substrates. Band $\mathrm{E}_{4}$ hydrolysed $\alpha$ - and $\beta$-naphthyl esters and reacted slightly with indoxyl acetate. Band $\mathrm{E}_{5}$ hydrolysed strongly $\alpha$ - and $\beta$-naphthyl acetates and, to a lesser extent, other substrates. Band $\mathrm{E}_{4}$ remained stable after incubation for $10 \mathrm{~min}$ at $60^{\circ} \mathrm{C}$, whereas band $E_{5}$ was partly inactivated under the same conditions. Band $\mathrm{E}_{6}$ hydrolysed $\beta$-naphthyl acetate and butyrate and reacted slightly with other substrates. Two other bands $\mathrm{E}_{\alpha \mathrm{a}}$ and $\mathrm{E}_{\alpha \mathrm{b}}$ (Fig $1 b, c$ ) were detected by $\alpha$-naphthyl acetate and reacted slightly with indoxyl acetate. Band $E_{\alpha b}$ was weakly stained by $\beta$-naphthyl acetate. Bands $E_{2}, E_{4}$ and $E_{\alpha a}$ were resistant to $10^{-3} M-D F P$, whereas bands $E_{1}, E_{3}$, $\mathrm{E}_{5}, \mathrm{E}_{6}$ and $\mathrm{E}_{\alpha \mathrm{b}}$ were inhibited at this concentration.

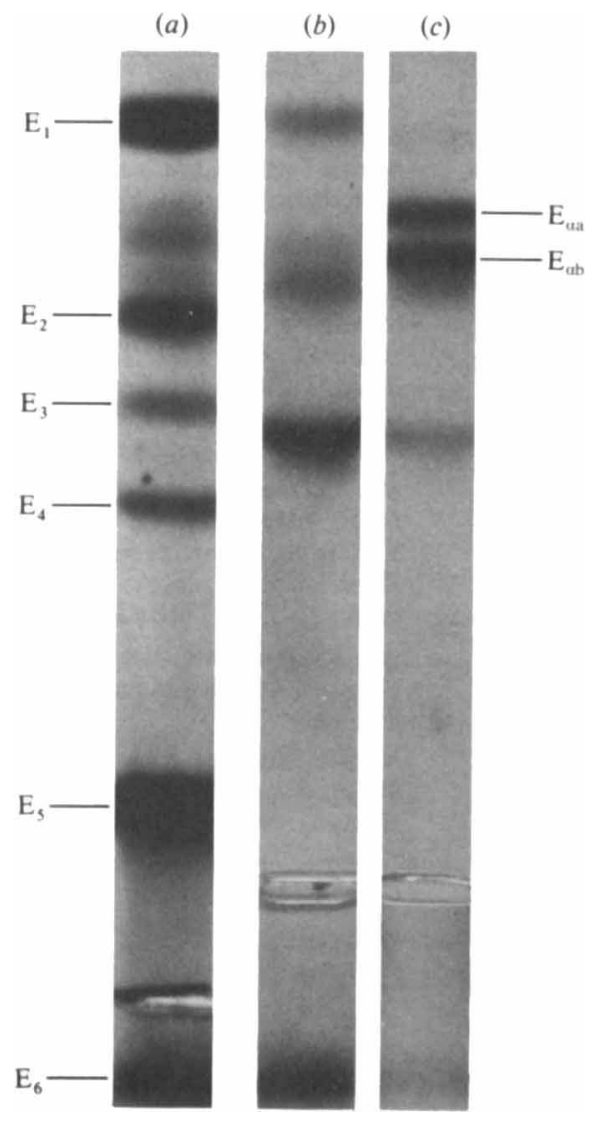

Fig. 1. Esterase bands of $Y$. enterocolitica revealed by horizontal acrylamide-agarose gel electrophoresis using $7 \%(\mathrm{w} / \mathrm{v})$ acrylamide. (a) Esterases of strain 1 (biotype 1 ) visualized by $\beta$-naphthyl acetate. (b) Esterases of strain 48 (biotype 5) visualized by $\beta$-naphthyl acetate. (c) Esterases of strain 48 visualized by $\alpha$-naphthyl acetate. 


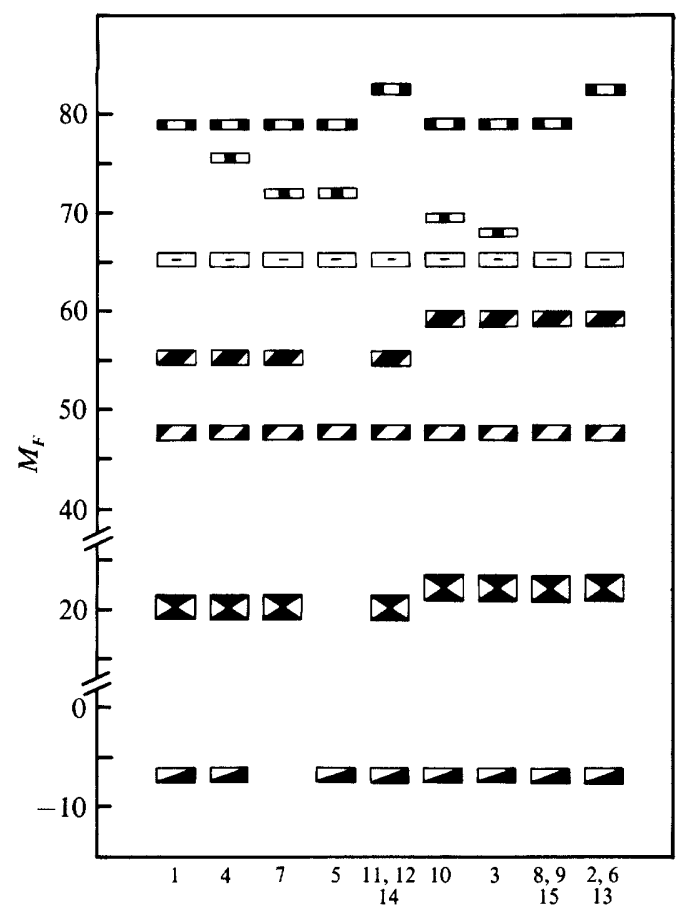

Fig. 2. Biotype 1 of $Y$. enterocolitica. Diagrammatic representation of electrophoretic esterase patterns of 15 strains (numbered as in Table 1). $\square, \mathrm{E}_{1}$ band; $\square, \mathrm{E}_{2}$ band; $\square, \mathrm{E}_{3}$ band; $\square, \mathrm{E}_{4}$ band; $\square, \mathrm{E}_{5}$ band; $\square, \mathrm{E}_{6}$ band; $\square, \mathrm{E}_{\alpha \mathrm{a}}$ band.

Figures 2, 3 and 4 show the electrophoretic distribution of esterases in the five biotypes. Bands $E_{1}, E_{2}$ and $E_{4}$ were identified in all biotypes whereas bands $E_{3}$ and $E_{5}$ were identified in biotype 1 only. Band $E_{7}$ of strains of biotypes 2 and 3 showed hydrolysing activity towards synthetic substrates similar to that observed for band $E_{6}$ of the other biotypes, but migrated to the anode. All strains of biotype 1 (Fig. 2) produced bands $E_{1}, E_{2}, E_{3}, E_{4}, E_{5}$ and $E_{6}$ with the exception of strain 5 for bands $E_{3}$ and $E_{5}$ and of strain 7 for band $E_{6}$. Bands $E_{2}$ and $E_{4}$ showed electrophoretic uniformity among the strains, whereas bands $E_{1}, E_{3}$ and $E_{5}$ displayed two types of mobility. Variations in mobilities of bands $E_{3}$ and $E_{5}$ defined two principal groups of strains: group A for strains 1, 4, 5, 7, 11, 12 and 14 and group B for strains 2, 3, 6, 8, 9, 10, 13 and 15. Band $E_{a \mathrm{a}}$ was detected in strains $3,4,5,7$ and 10 only. Strains of biotypes 2 and 3 (Fig. 3) showed identical mobilities for bands $E_{1}, E_{4}$ and $E_{7}$, respectively. In these two biotypes band $E_{1}$ was faint. Band $E_{2}$ of strains 28 to 33 (biotype 3 ) migrated slower than the corresponding band of other strains. Band $E_{\alpha a}$ was produced by all strains of biotype 3 . This band overlapped with band $\mathrm{E}_{\alpha \mathrm{b}}$, produced by strains 28 to 33 . Separation and characterization of bands were then achieved by using 6 or $8 \%(w / v)$ acrylamide (instead of $7 \%$ ) and by noting differences in DFP inhibition. Some additional bands were observed in biotype 2 ; band $\mathrm{E}_{\mathrm{a}}$ revealed by $\alpha$-naphthyl acetate in strains 17 to 19 ; band $E_{b}$ revealed by $\beta$-naphthyl acetate in strains 16,19 to 21,24 and 25 ; and band $E_{c}$ detected by $\alpha$-naphthyl butyrate in some strains of biotype 3 (not shown). Strains of biotypes 4 and 5 (Fig. 4) showed very similar patterns in mobilities of bands. However for strains of biotype 4 , (except strain 42) the band $E_{1}$ was faint or not detected whereas for strains of biotype 5 (except strain 49 ) the band $\mathrm{E}_{1}$ was well stained. In these two biotypes, band $\mathrm{E}_{6}$ migrated towards the cathode faster than the corresponding band of biotype 1, with the exception of strain 53 (biotype 5); in some strains, band $E_{2}$ was not detected.

Yersinia pseudotuberculosis. Five esterase bands, detected with $\beta$-naphthyl acetate and designated as $\mathrm{P}_{1}, \mathrm{P}_{2 \mathrm{a}}, \mathrm{P}_{2 \mathrm{~b}}, \mathrm{P}_{3}$ and $\mathrm{P}_{4}$ in order of decreasing mobilities, were defined (Fig. $5 a$ ). 


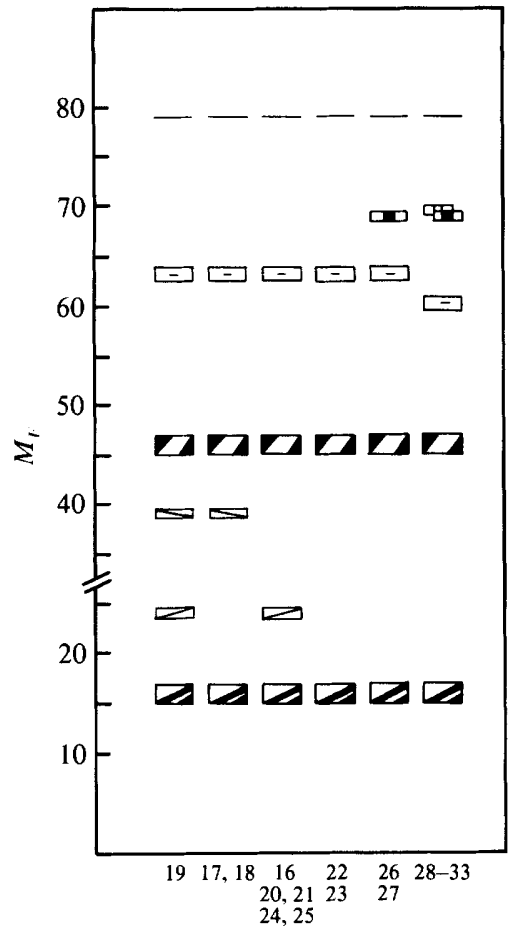

Fig. 3

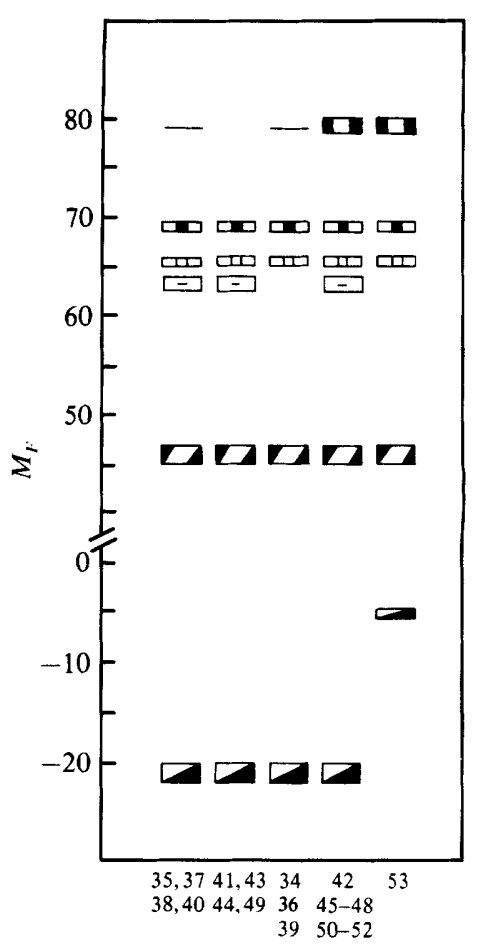

Fig. 4

Fig. 3. Biotypes 2 and 3 of $Y$. enterocolitica. Diagrammatic representation of electrophoretic esterase patterns of 18 strains. Key as in legend to Fig. 2, with the additions:,$- E_{1}$ faint band; $\square, E_{7}$ band; $\square, \mathrm{E}_{\alpha \mathrm{b}}$ band; $\square, \mathrm{E}_{\mathrm{a}}$ band; $\square, \mathrm{E}_{\mathrm{b}}$ band.

Fig. 4. Biotypes 4 and 5 of $Y$. enterocolitica. Diagrammatic representation of esterase patterns of 20 strains. Key as in legend to Figs 2 and 3.

Band $P_{1}$ was faint and reacted only with $\beta$-naphthyl acetate. Bands $P_{2 a}$ and $P_{2 b}$ hydrolysed $\beta$ naphthyl acetate and, slightly, $\alpha$-naphthyl acetate and $\beta$-naphthyl butyrate. Band $\mathrm{P}_{3}$ was active towards $\beta$-naphthyl esters. Band $\mathrm{P}_{4}$ was prominent, hydrolysing strongly $\alpha$ - and $\beta$-naphthyl acetates and to a lesser extent other substrates. The bands $P_{3}$ and $P_{4}$ remained active after $10 \mathrm{~min}$ at $60^{\circ} \mathrm{C}$. In addition, one fast-migrating band, $P_{\alpha a}$ (Fig. $5 b$ ), was detected with $\alpha-$ naphthyl acetate and indoxyl acetate. The esterases $P_{1}, P_{3}$ and $P_{4}$ were inhibited by $10^{-4} M-$ DFP, whereas esterases $P_{2 a}$ and $P_{2 b}$ were resistant to $10^{-3} M$-DFP. Figure 6 shows the electrophoretic distribution of esterases in strains of different serotypes. Individual mobilities were found to be identical among the strains for bands $P_{\alpha a}, P_{3}$ and $P_{4}$, respectively. Band $P_{\alpha a}$ was not recovered in strains 22 and 24 . Band $P_{4}$ was not recovered in strain 3 (serotype 1) and in strains 27 and 28 (serotype 5). Variations in mobility appeared only for band $P_{1}$ of strains 29 and 30 (serotype 6) and for bands $P_{2 a}$ and $P_{2 b}$ of strain 16 (serotype 3).

\section{Isoelectric focusing}

Strains indicated in Table 1 by asterisks were also analysed by isoelectrofocusing. A broad pH gradient ( 3.5 to 10 ) was initially employed but the two narrow pH gradients ( 4 to 6.5 and 5 to 8 ) were subsequently preferred because they gave higher resolution of esterase bands. The better results were obtained with $\alpha$-naphthyl acetate as substrate. Esterase bands of $Y$. enterocolitica strains resolved by isoelectric focusing had $\mathrm{pI}$ values ranging from 4.9 to 6.7 (Fig. 7). Esterase $E_{2}$ was visualized at $\mathrm{pH} 4.9$ for strains of biotype 1 but was not recovered for strains of other biotypes. Esterases $\mathrm{E}_{3}$ and $\mathrm{E}_{5}$ (biotype 1) showed two distinct isoelectric focusing patterns: one 


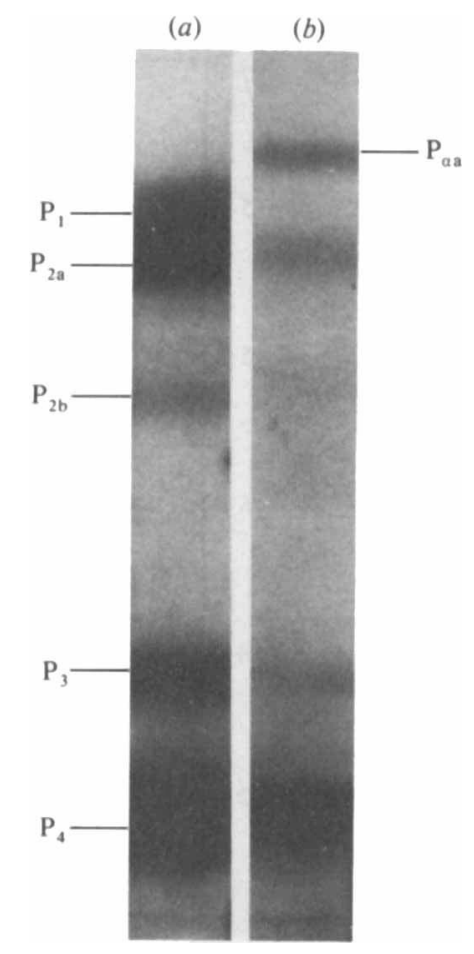

Fig. 5. Esterase bands of $Y$. pseudotuberculosis revealed by horizontal acrylamide-agarose gel electrophoresis using $7 \%(\mathrm{w} / \mathrm{v})$ acrylamide (strain 20$)$. (a) Esterases visualized by $\beta$-naphthyl acetate. (b) Esterases visualized by $\alpha$-naphthyl acetate.

for strains of group A with the higher pI values, another for strains of group B with the lower pI values. Esterase $\mathrm{E}_{4}$ focused at $\mathrm{pH} 6.4$ for strains of biotype 1 and at $\mathrm{pH} 6.6$ for strains of other biotypes. Esterase $E_{7}$ showed the same pI at 6.7 among the strains of biotypes 2 and 3 . Esterase $\mathrm{E}_{\alpha \mathrm{a}}$ focused uniformly at $\mathrm{pH} 5$ for strains of biotypes 3,4 and 5 , whereas esterase $\mathrm{E}_{\alpha \mathrm{b}}$ focused at $\mathrm{pH} 5 \cdot 25$ for strains of biotype 3 and at pH 5.4 for strains of biotypes 4 and 5 . Anodic band $\mathrm{E}_{1}$ and cathodic band $\mathrm{E}_{6}$ were not resolved by isoelectric focusing. However, using this technique two esterase bands, designated as $E_{F 1}$ and $E_{F 2}$, produced by strains of biotype 2 , were seen at $\mathrm{pH} 4.9$ and $5 \cdot 2$, respectively whereas these two bands were undetected by conventional polyacrylamideagarose gel electrophoresis.

For strains of $Y$.pseudotuberculosis, one major band and one minor band were visualized at $\mathrm{pH} 7$ and pH 5, respectively. The major band was identified as esterase $\mathrm{P}_{4}$ and the minor band as esterase $P_{\alpha \mathrm{a}}$. This latter band was diffuse, while esterase $E_{\alpha \mathrm{a}}$ of $Y$. enterocolitica focused as a sharp band. No detectable variation of esterase $\mathrm{pI}$ among the strains of $Y$.pseudotuberculosis was observed.

\section{Polyacrylamide gradient gel electrophoresis}

Esterase $\mathrm{E}_{4}$ produced by all strains of the five biotypes of $Y$. enterocolitica and esterase $\mathbf{P}_{4}$ produced by $Y$. pseudotuberculosis strains, two kinds of esterase resistant to heat, were investigated by polyacrylamide gradient gel electrophoresis for 500,1000,1500, 2000 and $2500 \mathrm{Vh}$. Figure 8 shows that asymptotic migration necessary to determine molecular weight (Rodbard \& Chrambach, 1971) was obtained with both $Y$. pseudotuberculosis and $Y$. enterocolitica. Using human serum albumin and Escherichia coli alkaline phosphatase as standard protein, the apparent molecular weights of esterases $E_{4}$ and $P_{4}$ were estimated to be approximately 52000 and 250000 , respectively. 

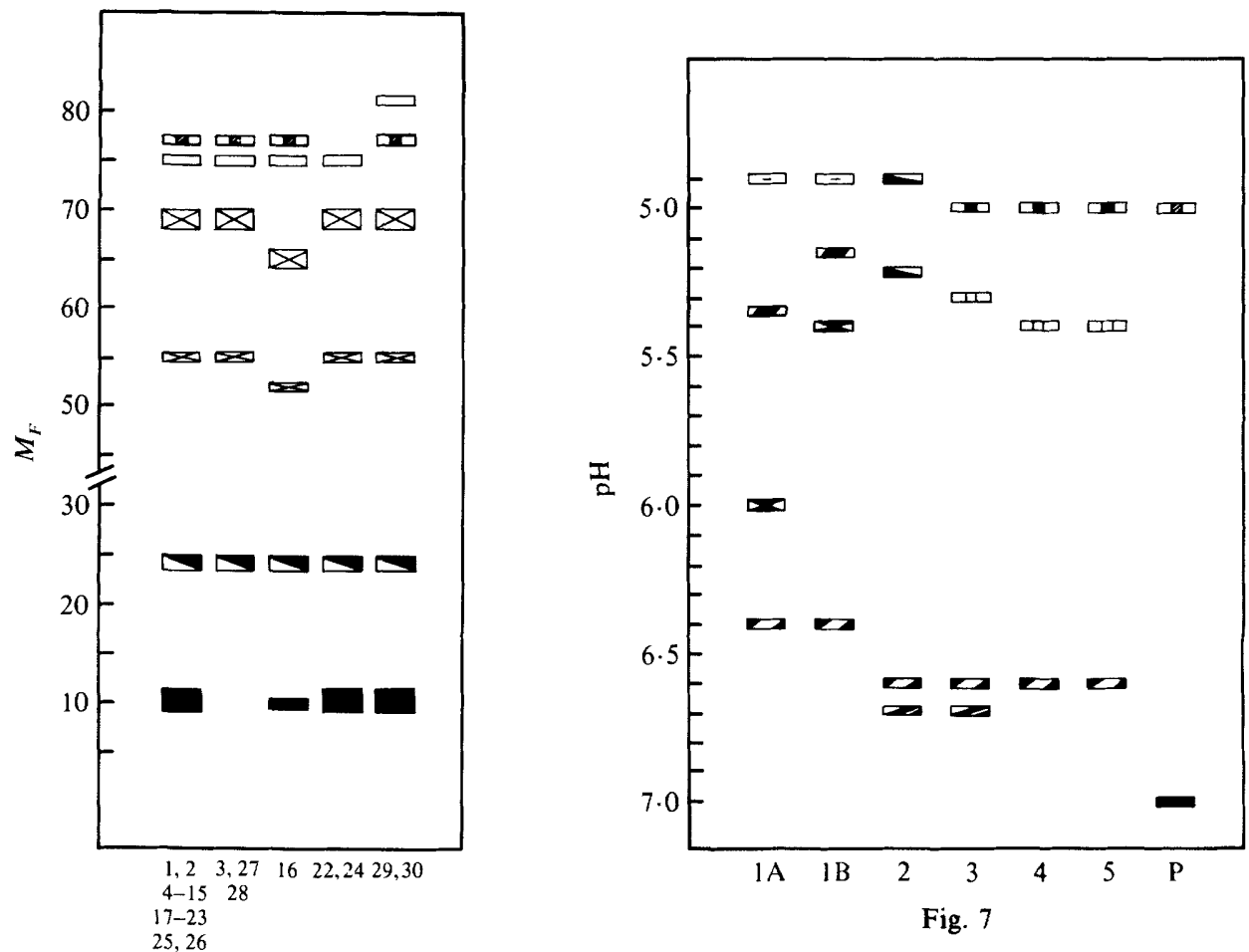

Fig. 6

Fig. 6. Diagrammatic representation of electrophoretic esterase patterns of 30 strains of $Y$. pseudotuberculosis (numbered as in Table 1). $\square, P_{1}$ band; $\bowtie, P_{2}$ band; $\square, P_{3}$ band; -, $\mathrm{P}_{4}$ band; $\infty, \mathrm{P}_{\alpha \mathrm{a}}$ band.

Fig. 7. Diagrammatic representation of isoelectric focusing in acrylamide gel (see Methods) of strains of $Y$. enterocolitica and $Y$. pseudotuberculosis. 1A, biotype 1, strains of group A; 1B, biotype 1, strains of group B; 2 , strains of biotype $2 ; 3$, strains of biotype $3 ; 4$, strains of biotype $4 ; 5$, strains of biotype 5 ; $\mathrm{P}$, strains of $Y$. pseudotuberculosis. Key as in legends to Figs 2, 3 and 6, with the addition: $\quad, \mathrm{E}_{\mathrm{F} 1}$ and $\mathrm{E}_{\mathrm{F} 2}$ bands.

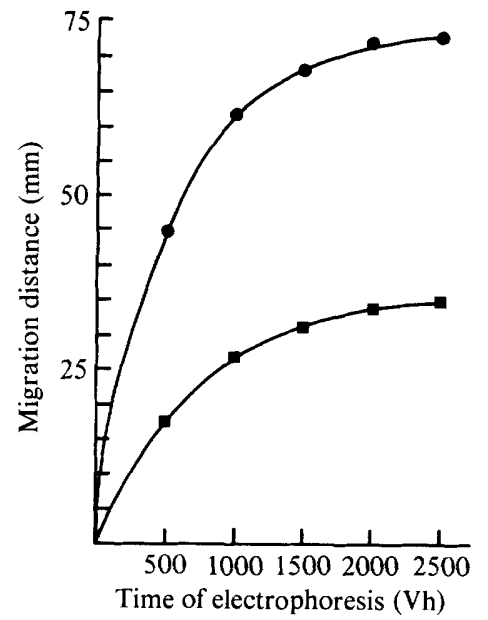

Fig. 8. Plots of mobilities of esterase $E_{4}$ from $Y$. enterocolitica (strain 1) and esterase $P_{4}$ from $Y$. pseudotuberculosis (strain 20) against time of electrophoresis in a polyacrylamide gradient gel. , Esterase $\mathrm{E}_{4} ; \mathbf{D}$, esterase $\mathrm{P}_{4}$. 


\section{DISCUSSION}

Polyacrylamide-agarose gel electrophoresis and thin-layer isoelectrofocusing demonstrated that strains of $Y$. enterocolitica and $Y$. pseudotuberculosis were characterized by distinct esterase banding patterns and that esterase data may be sufficient to identify the species of the 83 Yersinia strains analysed. This differentiation is supported by the molecular sieving effect in gradient gel electrophoresis which revealed that esterase $\mathrm{E}_{4}$ from $Y$. enterocolitica and esterase $\mathrm{P}_{4}$ from $Y$. pseudotuberculosis were very distinct in molecular weight. The distinctive esterase patterns of these organisms reflect their taxonomic distance as observed in DNA relationships (Brenner et al., 1976) and correlate with the specific differences in protein electrophoretograms (Hudson \& Quan, 1975), whereas only small interspecies differences were detected in cellular fatty acid composition (Jantzen \& Lassen, 1980).

On the basis of comparative distribution of electrophoretic bands and isoelectric points of esterases produced by strains of $Y$, enterocolitica, five principal zymotypes may be distinguished: zymotypes $\mathbf{A}$ and $\mathbf{B}$ for strains of biotype 1, zymotypes $\mathrm{C}$ and $\mathrm{D}$ for strains of biotypes 2 and 3 , respectively, and zymotype $E$ for strains of both biotypes 4 and 5 (Table 2). Zymotypes $A$ and $B$ were distinguishable from the other zymotypes by the presence of bands $E_{3}$ and $E_{5}$ and by differences in mobility of band $E_{2}$. Zymotypes $C, D$ and $E$ appeared similar in terms of the $E_{1}$ and $E_{4}$ band mobilities and in terms of $E_{4}$ band pI. Strains of biotype 2 differed from strains of biotype 3 by the absence of bands $E_{\alpha \mathrm{a}}$ and $\mathrm{E}_{\alpha \mathrm{b}}$ and by the presence of two esterase bands detected by isoelectric focusing and not recovered by electrophoresis. Strains of biotypes 2 and 3 differed from strains of biotypes 4 and 5 by the presence of band $E_{7}$ and absence of band $E_{6}$. According to electrophoretic and isoelectric focusing patterns of esterases, strains of biotypes $2,3,4$ and 5 appear to be more closely related to one another than to strains of biotype 1 , as was observed with $\beta$-lactamase electrofocusing patterns (Wauters, 1981).

Variations in number or in mobility of bands observed respectively within each biotype of $Y$. enterocolitica and within some serotypes of $Y$. pseudotuberculosis could represent an additional marker for epidemiological analysis.

Table 2. Distribution of esterase bands in the five biotypes of Y. enterocolitica

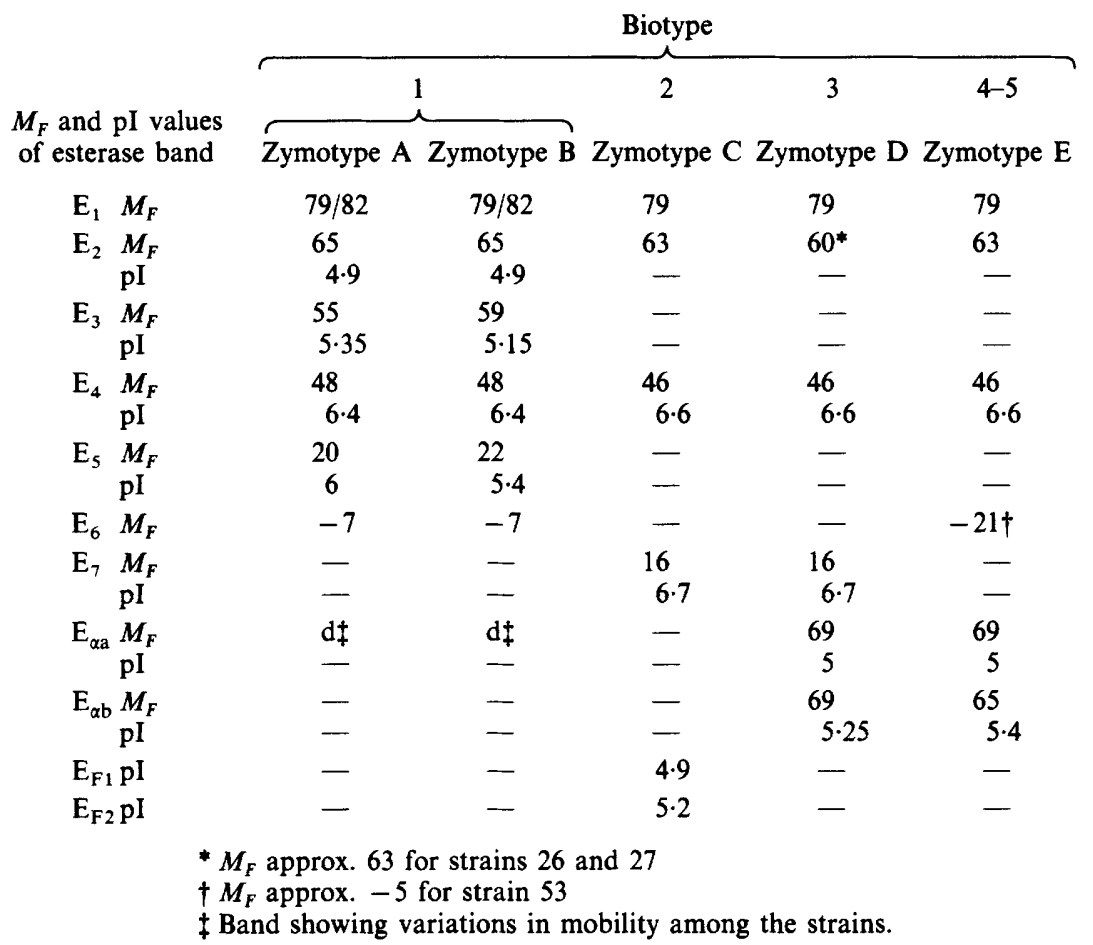


The authors thank Professeur H. H. Mollaret, Docteur H. Bercovier and Docteur C. Richard for strains, and Madame C. Gaillard and Madame N. Hautier for technical assistance. This work was supported by grants from the Conseil Scientifique de la Faculté Xavier Bichat (Université Paris VII) and from the Fondation pour la Recherche Medicale Française.

\section{REFERENCES}

Bercovier, H., BrenNer, D. J., Ursing, J., SteigerWalt, A. G., Fanning, G. R., Alonso, J. M., Carter, G. P. \& Mollaret, H. H. (1980a). Characterization of Yersinia enterocolitica sensu stricto. Current Microbiology 4, 201-206.

Bercovier, H., Ursing, J., BrenNeR, D. J., Steigerwalt, A. G., Fanning, G. R., Carter, G. P. \& Mollaret, H. H. (1980b). Yersinia kristensenii: a new species of Enterobacteriaceae composed of sucrose-negative strains (formerly called atypical Yersinia enterocolitica or Yersinia enterocolitica-like). Current Microbiology 4, 219-224.

Brenner, D. J., Steigerwalt, A. G., Falcao, D. P., WEAVER, R. E. \& FANNING, G. R. (1976). Characterization of Yersinia enterocolitica and Yersinia pseudotuberculosis by deoxyribonucleic acid hybridization and by biochemical reactions. International Journal of Systematic Bacteriology 26, 180-194.

BrenNer, D. J., URSing, J., Bercovier, H., Steigerwalt, A. G., Fanning, G. R., Alonso, J. M. \& MollareT, H. H. (1980a) Deoxyribonucleic acid relatedness in Yersinia enterocolitica and Yersinia enterocolitica-like organisms. Current Microbiology 4, 195-200.

Brenner, D. J., Bercovier, H., Ursing, J., Alonso, J. M., Steigerwalt, A. G., Fanning, R., Carter, G. P. \& Mollaret, H. H. (1980b). Yersinia intermedia: a new species of Enterobacteriaceae composed of rhamnose-positive, melibiose-positive, raffinose-positive strains (formerly called Yersinia enterocolitica or Yersinia enterocolitica-like). Current Microbiology 4, 207-212.

Goullet, PH. (1980a). Distinctive electrophoretic patterns of esterases from Klebsiella pneumoniae, $K$. oxytoca, Enterobacter aerogenes and $E$. gergoviae. Journal of General Microbiology 117, 483-491.

Goullet, PH. (1980b). Esterase electrophoretic pattern relatedness between Shigella species and Escherichia coli. Journal of General Microbiology 117, 493500.

Goullet, Ph. (1981). Characterization of Serratia odorifera, $S$. fonticola and $S$. ficaria by the electrophoretic patterns of their esterases. Journal of General Microbiology 127, 161-167.

HaRvey, S. \& PICKeTt, M. J. (1980). Comparison of Adansonian analysis and deoxyribonucleic acid hybridization results in the taxonomy of Yersinia enterocolitica. International Journal of Systematic Bacteriology 30, 86-102.
Hudson, B. W. \& QuaN, T. J. (1975). Electrophoretic studies of the Yersiniae. American Journal of Tropical Medicine and Hygiene 24, 968-973.

JANTZEN, E. \& LASSEN, J. (1980). Characterization of Yersinia species by analysis of whole-cell fatty acids. International Journal of Systematic Bacteriology 30, 421-428.

KaneKo, K. I. \& Hashimoto, N. (1982). Five biovars of Yersinia enterocolitica delineated by numerical taxonomy. International Journal of Systematic Bacteriology 32, 275-287.

Nicolle, P., Mollaret, H. H., Hamon, Y. \& VieU, J. F. (1967). Etude lysogénique, bacteriocinogénique et lysotypique de l'espèce Yersinia enterocolitica. Annales de l'Institut Pasteur 112, 86-92.

RODBARD, D. \& CHRAMBACH, A. (1971). Estimation of molecular radius, free mobility and valence using polyacrylamide gel electrophoresis. Analytical Biochemistry 40, 95-134.

THAL, E. (1954). Untersuchungen über Pasteurella pseudotuberculosis unter besonderer Berücksichtigung ihres immunologischen Verhaltens. Veterinary thesis, Lund, Berlingska boktryckeriet.

Ursing, J., Brenner, D. J., Bercovier, H., FANNING, G. R., Steigerwalt, A. G., Brault, J. \& MolLARET, H. H. (1980). Yersinia frederiksenii: a new species of Enterobacteriaceae composed of rhamnose positive strains (formerly called atypical Yersinia enterocolitica or Yersinia enterocolitica-like). Current Microbiology 4, 213-217.

VESTERBERG, O. \& SVENSSON, H. (1966). Isoelectric fractionation, analysis and characterization of ampholytes in natural $\mathrm{pH}$ gradients. IV. Further studies on the resolving power in connection with separation of myoglobins. Acta chemica scandinavica 20, 820834.

WaUters, G. (1970) Contribution à l'étude de Yersinia enterocolitica. Ph.D. thesis, Vander, Louvain, Belgium.

Wauters, G., Le Minor, L. \& Chalon, A. M. (1971). Antigènes somatiques et flagellaires de Yersinia enterocolitica. Annales de l'Institut Pasteur 120, 631642.

WaUters, G. (1981). Correlation between taxonomy, serology and biochemistry of Yersinia enterocolitica. In Psychrotrophic Microorganisms in Spoilage and Pathogenicity, pp. 387-391. Edited by G. Wauters, T. A. Roberts, G. Hobbs, J. H. B. Christian \& N. Skovgaard. London: Academic Press. 